\title{
Study on safe environment : Do women have any role
}

\section{K. GHADEI, PUSHPENDRA KUMAR AND RAM NIWAS}

Article Chronicle :

Received:

12.09.2013;

Accepted :

26.11.2014
SUMMARY : In developing areas of the world, women are considered the primary users of natural resources like land, forest and water because they are responsible for gathering food, fuel, and fodder. Although in these countries, women mostly can't own the land and farms outright, they are the ones who spend most of their time working on the farms to feed the household. Shouldering this responsibility leads them to learn more about soil, plants and trees and not misuse them. Although, technological inputs increase male involvement with land. Many of them leave the farm to go to cities to find jobs; so women become increasingly responsible for an increasing portion of farm tasks. These rural women tend to have a closer relationship with land and other natural resources, which promotes a new culture of respectful use and preservation of natural resources and the environment, ensuring that the following generations can meet their needs.

HOW TO CITE THIS ARTICLE : Ghadei, K., Kumar, Pushpendra and Niwas, Ram (2014). Study on safe environment: Do women have any role. Asian J. Environ. Sci., 9(2): 100-102.

Key Words :

Gender, Feed, Women, Environment 